\title{
Politycznie zaangażowane treści w japońskich fanowskich produkcjach wideo inspirowanych serią Atak Tytanów
} Politically engaged narratives in Japanese video fan productions
inspired by Attack on Titan

Streszczenie: Łącząca w sobie postapokaliptyczne oraz fantastyczne wątki seria animowana Atak Tytanów jest jednym z najpopularniejszych na japońskim rynku tytułów ostatnich lat. Stała się inspiracją dla licznych prac fanowskich, w tym również wielu fan videos (fanowskich produkcji wideo). Artykuł przedstawia, w jaki sposób twórcy fan videos wykorzystują nawiązania do Ataku Tytanów (w szczególności muzykę z serialu oraz sposób edycji materiału wideo) w celu promocji konserwatywnych i nacjonalistycznych idei politycznych. Prace takie bardzo pozytywnie przedstawiają potencjalną remilitaryzację Japonii, propagują negatywny wizerunek krajów sąsiedzkich (Korei Południowej, Chińskiej Republiki Ludowej) jako zagrożenia oraz wyrażają bezpośrednie poparcie dla rządu premiera Abe Shinzō. W artykule omówiono, jak w odróżnieniu od liberalnych młodych Japończyków, zaangażowanych w merytoryczną dyskusję oraz działalność polityczną w świecie rzeczywistym, konserwatywna młodzież wykorzystuje popkulturę oraz internet jako narzędzia „fanowskiej” agitacji politycznej przeprowadzanej w przystępnej, atrakcyjnej i emocjonalnej formie fan video, docierającej do szerokiego grona odbiorców dzięki wykorzystaniu popularności Ataku Tytanów.

Słowa kluczowe: Japonia, popkultura, nacjonalizm, kultura fanowska, fan videos, wojskowość

Produkcje fanowskie kojarzone są przede wszystkim z twórczością inspirowaną dziełami kultury popularnej oraz masowej. Nawiązujące do gier komputerowych, komiksów, filmów czy seriali, prace fanów reinterpretują fabuły znane z komercyjnych dzieł, stanowią ich parodie i rozszerzenia, przedstawiają alternatywne losy bohaterów, bywają też artystycznym hołdem złożonym oryginałowi. Na gruncie akademickim twórczość tego typu jest najczęściej analizowana pod 
kątem roli, jaką odgrywa w kulturze fanowskiej oraz jako forma zaangażowania w fikcyjne narracje ${ }^{1}$. Produkcje fanowskie mogą jednak wychodzić poza świat popkultury, nawiązując do wydarzeń historycznych, politycznych oraz zjawisk społecznych, stając się dla wielu młodych ludzi sposobem na publiczne wyrażenie oraz promocję zainteresowań i opinii.

Jednym z krajów, w którym produkcje fanowskie zostały rozpoznane jako istotny element kultury popularnej, jest Japonia. Kreatywna twórczość fanów stała się tam integralną częścią rynku mediów ${ }^{2}$, a dystrybucja tego typu treści, nawet jeśli wykorzystują elementy prawnie chronionych dzieł komercyjnych, nie jest z reguły ograniczana przez właścicieli praw autorskich ${ }^{3}$.

Najbardziej rozpowszechnioną formą takich produkcji są fanowskie komiksy (dōjinshi), będące - ze względu na dużą sprzedaż - istotnym elementem rynku wydawniczego ${ }^{4}$. Popularnością cieszą się jednak również fanowskie gry, utwory muzyczne, grafiki oraz montaże filmowe.

W niniejszym artykule przeanalizowano jedną z form produkcji fanowskich, znaną jako fan video (dalej: fanvid), czyli krótkie utwory wykorzystujące fragmenty tekstów kultury. Omawiane filmy, stworzone przez japońskich fanów, nawiązują na różne sposoby do animowanej serii telewizyjnej Atak Tytanów (Shingeki no Kyojin). Ważnym elementem łączącej motywy fantastyczne i postapokaliptyczne serii jest pozytywne przedstawienie formacji wojskowych, a więc motyw, który został wykorzystany przez odbiorców o konserwatywnych poglądach politycznych. Liczne fanvidy nawiązujące do Ataku Tytanów stanowią też formę wyrażenia poparcia dla remilitaryzacji Japonii, co uwidacznia się w gloryfikacji wizerunku Japońskich Sił Samoobrony (JSDF), przedstawieniu państw ościennych Japonii jako zagrożenia oraz poparciu dla premiera Abe Shinzō ${ }^{5}$ jako

1 Zob. H. Jenkins, Textual Poachers: Television Fans and Participatory Culture, London 1992; M. Hills, Fan Cultures, London 2003; Fan Fiction and Fan Communities in the Age of the Internet: New Essays, pod red. K. Busse i K. Hellekson, Jefferson 2006; H. Jenkins, Convergence Culture: Where Old and New Media Collide, New York 2006; The Adoring Audience: Fan Culture and Popular Media, pod red. L.A. Lewis, New York 2006; R.A. Reid, Remaking Texts, Remodeling Scholarship, [w:] Film Remakes, Adaptations and Fan Productions, pod red. K. Loock i C. Verevis, Basingstoke 2012, s. 179-196.

2 M. Ito, Technologies of the Childhood Imagination: Yu-Gi-Oh!, Media Mixes, and Everyday Cultural Production, [w:] Structures of Participation in Digital Culture, pod red. J. Karaganisa, Nowy Jork 2007, s.100-101.

${ }^{3} \mathrm{~N}$. Noppe, The cultural economy of fanwork in Japan: dōjinshi exchange as a hybrid economy of open source cultural goods [praca doktorska], Leuven 2014, s. 271-275.

4 Rynek dōjinshi był w 2014 roku wyceniany na ponad 70 miliardów jenów, czyli ponad 2 miliardy złotych. Zob. tamże s. 2.

$5 \mathrm{~W}$ niniejszym artykule imiona i nazwiska zapisane są w tradycyjnej kolejności japońskiej, czyli nazwisko przed imieniem. 
silnego wodza narodu. W artykule omówiono, w jaki sposób konserwatywni fani łączą estetykę i narrację Ataku Tytanów z przesłaniem politycznym, wykorzystując krótką, przemawiającą do emocji i łatwą w odbiorze formę fanvidu.

\section{Kulturalna działalność opozycyjna młodzieży wobec polityki rządu Abe Shinzō}

Abe Shinzō, wybrany na urząd premiera z ramienia Partii Liberalno-Demokratycznej (PLD) w grudniu 2012 roku, znany jest z nacjonalistycznych poglądów, obejmujących między innymi rewizjonizm historyczny oraz akceptację dla działalności prawicowych ekstremistów ${ }^{6}$. Polityka Abe obejmuje dążenie do remilitaryzacji Japonii z uwzględnieniem zmiany obowiązującej, pacyfistycznej konstytucji ${ }^{7}$, bliską współpracę ze Stanami Zjednoczonymi oraz produkcję i eksport energii atomowej ${ }^{8}$. Z tego względu krytycy rządu Abe zarzucają mu między innymi ograniczanie wolności słowa w mediach oraz brak poszanowania dla zasad demokracji ${ }^{9}$. Dotyczy to zwłaszcza decyzji podjętych przez rząd PLD, które spotkały się z wyjątkowo silną krytyką społeczeństwa japońskiego, wywołując fale protestów: przyjęcia w grudniu 2013 roku kontrowersyjnej ustawy o ochronie tajemnic państwowych, potencjalnie ograniczającej dostęp obywateli do informacji o działaniach rządu; a kilka miesięcy później rozpoczęcia rozmów o reinterpretacji konstytucji pozwalającej Japońskim Siłom Samoobrony (Japanese Self-Defence Forces, dalej: JSDF) na czynne wsparcie sojuszników w misjach wojskowych w ramach „obrony kolektywnej” ${ }^{10}$. Decyzje rządu związane z dostępem do informacji oraz sferą wojskową, podjęte w latach 2013-2015, spotkały się ze zdecydowanie krytyczną reakcją młodzieży, a w szczególności studentów ${ }^{11}$.

6 J. Kingston, Extremists Flourish in Abe's Japan, „The Asia-Pacific Journal: Japan Focus” 2014, 12(44), nr 2, [online:] https://apjjf.org/-Jeff-Kingston/4809/article.html [data dostępu: 30. 05.2018].

7 Artykuł 9 obowiązującej od 1947 roku konstytucji Japonii mówi o wyrzeczeniu się wojny oraz posiadania potencjału wojskowego. Zob. M. Stańczyk, Artykut 9. Konstytucji Japonii dotyczacy wyrzeczenia się wojny i posiadania sił zbrojnych - motywy, kierunki i potrzeby interpretacji, „Rocznik Bezpieczeństwa Narodowego” 2008, nr 3, s.167.

8 G. McCormack, Japan: Prime Minister Abe Shinzo's Agenda, „The Asia-Pacific Journal: Japan Focus", 2016, 14(24), nr 1, [online:] https://apjjf.org/2016/24/McCormack.html [data dostępu: 30. 05.2018].

9 Press Freedom in Contemporary Japan, pod red. J. Kingstona, Nowy Jork 2016.

10 Wcześniej JSDF mogły angażować się w walkę tylko w przypadku bezpośredniego zagrożenia Japonii. Nowe przepisy zostały przyjęte i wprowadzone w życie w marcu 2016 roku.

${ }^{11}$ N. Manabe, Uprising: Music, Youth, and Protest Against the Policies of the Abe Shinzō Government, „The Asia-Pacific Journal: Japan Focus” 2014, 12(32), nr 3, [online:] https://apjjf. org/2014/12/32/Noriko-Manabe/4163/article.html[data dostępu: 30. 05.2018]. 
Politycznie zaangażowane stowarzyszenia studenckie powstawały w celu zatrzymania forsowanych przez rząd zmian prawnych, a ich działalność kończyła się (w przypadku omawianych tutaj przykładów - niepowodzeniem), kiedy nowe prawo wchodziło w życie. Projekt ustawy o ochronie tajemnic państwowych zaowocował powstaniem w 2013 roku organizacji Studenci Przeciw Ustawie o Ochronie Tajemnic Państwowych (Students Against Secret Protection Law, SASPL). Po porażce organizacja w 2015 roku przekształciła się w SEALDs (Students Emergency Action for Liberal Democracy, Pogotowie Studenckie na Rzecz Liberalnej Demokracji), bezskutecznie sprzeciwiające się wprowadzeniu w życie prawa zezwalającego JSDF na udział w konfliktach zbrojnych w ramach obrony kolektywnej. Główną formą działalności stowarzyszeń była organizacja antyrządowych marszów i demonstracji przyciągających młodych uczestników nie tylko głoszonymi hasłami, ale również ciekawą oprawą muzyczną oraz „rozrywkowym”, wręcz „klubowym” klimatem ${ }^{12}$. Nie przełożyło się to jednak na sukces przedsięwzięcia, a SEALDs - po głośnej, lecz bezskutecznej walce - zakończyło swoją działalność w roku 2016. Ostatnią większą grupą, zrzeszającą nie tylko studentów, ale również absolwentów, naukowców oraz artystów, było utworzone w 2011 roku Civitas. Grupa stawiała sobie za cel edukację dotyczącą alternatywnych źródeł energii oraz szerzenie i wymianę informacji na temat potencjalnych zagrożeń wynikających z propozycji zmian prawnych proponowanych przez rząd Abe. Choć Civitas oficjalnie nie zamknęło działalności, ich oficjalny blog jest obecnie (czerwiec 2018) dostępny tylko dla użytkowników zaproszonych przez moderatora, brakuje również danych o jakichkolwiek planowanych działaniach.

Młodzi działacze promowali swoje idee na różne sposoby. W szczytowym momencie aktywności SEALDs współpracowało z mediami, zapraszając przedstawicieli telewizji i prasy na wywiady oraz konferencje prasowe, a także organizując wydarzenia, które przyciągały medialną uwagę $e^{13}$. Grupa skupiała się na fizycznej obecności oraz aktywnym działaniu na ulicach miasta. Internetowa promocja SEALDs bazowała na tekstach informacyjnych oraz montażach wideo, które zawierały nagrania dokumentujące działalność organizacji. Filmy dostępne na oficjalnej stronie SEALDs ${ }^{14}$ oraz kanale Stowarzyszenia na YouTubie to przede wszystkim wysokiej jakości nagrania przemówień z demonstracji, które pozwalają widzowi na szybkie zorientowanie się w ideach reprezentowanych przez twórców.

12 Tamże.

${ }^{13}$ J. Kingston, SEALDs: Students Slam Abe's Assault on Japan's Constitution, „The Asia-Pacific Journal: Japan Focus", 2014, 13(36), nr 1, [online:] https://apjjf.org/-Jeff-Kingston/4371 [data dostępu: 31. 05.2018].

${ }_{14}$ SEALDs, Oficjalna strona Internetowa, [online:] https://www.sealds.com/ [data dostępu: 31.05.2018] 
Przedstawiają również nagrania z wieców i protestów, z wkomponowanymi w nie napisami freedom (wolność) czy democracy (demokracja) ${ }^{15}$. Zawierają informacje o datach i miejscach kolejnych protestów, zachęcając widzów do aktywnego w nich uczestnictwa. Odnaleźć w nich można także treści edukacyjne, przystępnie omawiające zagadnienia prawne. Publikowano też, stworzone przez zaangażowanych artystów, oryginalne utwory muzyczne, które miały być promocją ich idei. Na przykład utwór To be podkreśla wartość pokojowych metod rozwiązywania konfliktów w odniesieniu do powojennej historii Japonii oraz fundamentalną rolę artykułu 9 konstytucji (o wyrzeczeniu się wojny) ${ }^{16}$. Antykomunistyczne przesłanie wybrzmiało mocno w warstwie wizualnej, operującej ciągiem scen przedstawiających zrzucenie bomby atomowej na Hiroszimę, postać Ghandiego oraz studenta stającego na drodze czołgu na placu Tian'anmen.

Chociaż młodzi aktywiści nie ignorują zupełnie siły internetu w promocji swoich idei, ich wysiłki skupione są przede wszystkim na świecie rzeczywistym i przejawiają się w organizacji protestów oraz merytorycznej edukacji na temat konkretnych zmian w prawie. Sieć służy im nie tyle do wyrażania opinii, co jest narzędziem informacyjnym oraz drogą dotarcia do osób, które mogą potencjalnie zainteresować się ruchem i wesprzeć go konkretnymi czynami. Ponadto w swojej działalności nie wykorzystują nawiązań do popkultury, a ich produkcje nie mogą być zaliczone do fanowskich.

\section{Fandom zbuntowany - fanvid jako narzędzie narracyjnej (re)interpretacji}

Fani dzieł popkultury niejednokrotnie wykorzystywali wspólne zainteresowania w celu rozpoczęcia oraz promocji kampanii społecznych, takich jak akcje dobroczynne (wsparcie konkretnych instytucji pomocą finansową) bądź upamiętnienie ofiar zamachów ${ }^{17}$. Już sama przynależność do określonej społeczności fanowskiej mogła być traktowana jako manifestacja poglądów politycznych ${ }^{18}$.

${ }^{15}$ Język angielski był szeroko wykorzystywany w całości kampanii, nie tylko w filmach promocyjnych, lecz również powszechnie na transparentach. Jest to widoczne na przykład na tym nagraniu z demonstracji SEALDs: https://www.youtube.com/watch?v=qT5NI8-EpnM

16 SEALDs FKA SASPL, SEALDs, To be, 14.08.2016, [film online:] https://www.youtube. com/watch?time_continue $=70 \& v=X 16 G$ toAb_dM [data dostępu: 31.05 .2018$]$.

${ }_{17}$ M. M. Brough i S. Shresthova, Fandom Meets Activism: Rethinking Civic and Political Participation, „Transformative Works and Cultures” 2012, nr 10, [online:] http://journal.transformativeworks.org/index.php/twc/article/view/303/265 [data dostępu: 29.05.2018].

18 P. Siuda, In Pursuit of Pop Culture: Reception of pop culture in the People's Republic of Poland as Opposition to the Political System - Example of the science fiction fandom, „European Journal of Cultural Studies" 2014, 17 (2), s. 187-208. 
Fandom kojarzony jest często z potrzebą eskapizmu oraz formą przeciwstawienia się otaczającej rzeczywistości ${ }^{19}$. Japońscy fani, których prace omawiane będą w tym artykule, wyrażają jednak w swojej twórczości opinie prorządowe, zgodne z konserwatywną polityką Abe. Mimo to wciąż potrafią stawiać się „W opozycji do mainstreamu”, głosząc konieczność walki z „antyjapońskimi” mediami, czyli liberalną prasą i telewizją, które postrzegane są jako najsilniejszy głos w publicznej debacie dotyczącej tak historii, jak i bieżącej polityki Japonii. Prowadzi to do paradoksalnej sytuacji, w której zgodne z rządową linią polityczną poglądy postrzegane są przez tę grupę jako sprzeciw wobec narracji dominującej w krajowych mediach.

Jak pokazuje przykład SEALDs, montaże wideo należą do popularnych form promocji poglądów w internecie. Łatwe w dystrybucji (dzięki darmowym platformom typu YouTube), nie wymagają również od twórców umiejętności innych niż podstawowa obsługa programów do edycji filmów. Część osób o konserwatywnych bądź nacjonalistycznych zapatrywaniach publikuje montaże, prezentując swoje poglądy w formie ustnej bądź pisemnej, które uzupełnia się zdjęciami lub fragmentami programów informacyjnych. Inni decydują się na wprowadzenie popkulturowych nawiązań w celu wzmocnienia ideologicznego przekazu. Powstałe w ten sposób montaże wpisują się w szeroką kategorię fanowskich produkcji wideo, czyli fanvidów.

Praktyka tworzenia fanvidów miała swój początek w 1975 roku, kiedy Kandy Fong przedstawiła pierwszą fanowską prezentację, zmontowaną przy użyciu materiałów z kaset $\mathrm{VHS}^{20}$. Przez kolejne dwie dekady fanvidy były dystrybuowane głównie w małym gronie przyjaciół bądź na konwentach. Już na tym etapie, w 1992 roku, praktyka ta została zauważona przez Henry'ego Jenkinsa, który poświęcił jej rozdział w jednej z pierwszych szerszych analiz kultury fanowskiejej. Zarówno skala produkcji, jak i konsumpcji fanvidów wzrosła jednak gwałtownie wraz z upowszechnieniem się dostępu do internetu ${ }^{22}$, a w szczególności z chwilą powstania platformy YouTube w roku 2005. Według analizy Burgessa i Greena w 2009 roku fanvidy stanowiły $15 \%$ treści umieszczanych na YouTubie ${ }^{23}$.

${ }_{19}$ H. Jenkins, Star Trek: rerun, Reread, Rewritten: Fan Writing as Textual poaching, „Critical Studies in Mass Communication" 1988, 5 (2), s. 88-89.

20 T. Turk, „Your Own Imagination”: Vidding and Vidwatching as Collaborative Interpretation, „Film \& Film Culture” 2010, nr 5, s. 88.

${ }^{21}$ H. Jenkins, Textual Poachers: Television Fans and Participatory Culture, Londyn 1992, s. 228-254.

22 T. Turk, op. cit., s. 93.

23 J. Burgess i J. Green, YouTube: Online Video and Participatory Culture, Cambridge 2009, s.43. Liczba ta uwzględnia również anime music videos (AMV), podkategorię fanvidów, do tworzenia których materiałem źródłowym jest anime, czyli japońskie filmy i seriale animowane. AMV, 
Fanvidy, podobnie jak fan fiction, zaliczają się do form narracyjnych. Tisha Turk opisuje praktykę tworzenia fanowskich filmów jako proces, w którym twórca może podkreślić pewne aspekty historii przedstawionej w wizualnym materiale źródłowym, poddać je krytyce lub zreinterpretować ${ }^{24}$. Fanvidy postrzegane są jako narzędzie służące skierowaniu uwagi odbiorcy na postacie oraz wątki marginalizowane w dziele oryginalnym. Francesca Coppa podkreśla, że fanowskie filmiki tworzone są w większości przez kobiety, które wykorzystują tę okazję, aby wyeksponować ważne z ich perspektywy tematy, często ignorowane $\mathrm{w}$ tekście oryginalnym ${ }^{25}$.

Powyższe spojrzenie na fanvidy jest jednak zbyt wąskie w kontekście całokształtu zjawiska. W ramach zabaw z materiałem filmowym fani tworzą również fikcyjne zapowiedzi nieistniejących filmów, „ekranizują” swoje ulubione powieści czy też parodiują oryginał (nie bez zmiany dialogu lub dodania sceny zmieniającej wydźwięk całości na komiczny). Warstwa wizualna pochodzić może z filmów i seriali, ale fani wykorzystują też gry wideo, zdjęcia, materiały archiwalne i dokumentalne, grafiki, fragmenty reklam bądź oryginalne animacje. $\mathrm{Z}$ tego względu na potrzeby niniejszego artykułu definiuję fanvidy jako montaże w formie wideo nawiązujące w dowolny sposób do kultury popularnej ( w warstwie wizualnej lub dźwiękowej), powstałe wskutek inspiracji zewnętrznej (jako reakcja na tekst kultury, ale również z powodu fascynacji danym tematem, takim jak sport lub historia, tudzież znaną osobą: muzykiem, aktorem) oraz stworzone w ramach hobby, niekomercyjnie, jako środek służący autoekspresji. Definicja ta pozwalana dokonać rozróżnienia na fanvidy i inne, często bardzo do nich zbliżone, typy amatorskich montaży umieszczanych na internetowych platformach wideo.

Najpopularniejszym japońskim portalem, który pozwalaja na bezpłatne zamieszczanie i odtwarzanie plików wideo, jest NicoNico Dōga. Właśnie tutaj można znaleźć najwięcej fanowskich produkcji. Wymaga on jednak rejestracji, w związku z czym większość szczegółowo omawianych w niniejszym artykule

\footnotetext{
szczególnie popularne w Ameryce Północnej, odegrały istotną rolę w rozpowszechnianiu anime na Zachodzie oraz rozwoju społeczności fanowskiej skupionej wokół japońskiej. Zob. M. Itō, „As long as it's not Linkin Park Z": Popularity, Distinction, and Status in the AMV Subculture, [w:] Fandom Unbound Otaku Culture in a Connected World, pod red. M. Itō, D. Okabe i I. Tsuji, New Haven 2012, s. 275-298.

${ }^{24}$ T. Turk, Metalepsis in Fan Vids and Fan Fiction, [w:] Metalepsis in Popular Culture, pod red. K. Kukkonen i S. Klimek, Berlin 2011, s. 84-85.

${ }^{25}$ F. Coppa, Women, „Star Trek”, and the early development of fannish vidding. "Transformative Works and Cultures" 2008, nr 1, [online:] http://journal.transformativeworks.org/index.php/ twc/article/view/44 [data dostępu: 29.05.2018].
} 
fanvidów to prace zamieszczone na międzynarodowej platformie YouTube, dostępnej dla wszystkich użytkowników Internetu bez ograniczeń.

Istnieje kilka sposobów, jakie fani wykorzystują do wyrażania i promocji swoich poglądów. Na YouTubie dostępne są między innymi fanvidy, które prezentują, za pomocą motywu muzycznego z serii filmów Godzilla, zagrożenie, jakim dla Japonii jest „antyjapońska” retoryka liberalnych mediów. Ten sam temat podejmują również montaże wykorzystujące na przykład zapowiedź gry wideo Ace Combat 6: Fires of Liberation, w której napisy będące tłumaczeniem anglojęzycznej ścieżki dialogowej zastąpiono tekstem wyjaśniającym widzowi szkodliwe działanie popularnych mediów, usiłujących sterować japońską opinią publiczną za pomocą kłamstw na temat rządu.

Związek między fandomem a polityką widoczny jest najwyraźniej w debacie dotyczącej obronności państwa. Wykorzystując pozytywną reprezentację wojska w serialach animowanych takich jak Space Battleship Yamato (1974-1975), Zipang (2004-2005) czy Kantai Collection (2015), fani tworzą montaże gloryfikujące JSDF. Mimo iż organizacja prawnie nie ma statusu wojska ${ }^{26}$, a do jej zadań należą przede wszystkim misje niebojowe, fanvidy ukazują JSDF w sposób bardzo dynamiczny, w trakcie ćwiczeń bojowych, a także kładą duży nacisk na wykorzystanie nowoczesnego sprzętu wojskowego. Powstałe montaże odwołują się często do historii Japonii oraz dumy narodowej, wpisując się w rządową retorykę promującą remilitaryzację kraju poprzez zwiększenie uprawnień JSDF oraz reinterpretację artykułu 9 konstytucji. Choć tematem spornym jest, czy samo propagowanie wizerunku JSDF jako silnej organizacji wojskowej jest już przejawem zaangażowania politycznego, to część fanów idzie jeszcze dalej, przekładając fikcyjne narracje dzieł popkultury na rzeczywistość społeczno-polityczną Japonii, aby dać wyraz poparciu działaniom rządu. Zabieg ten jest wyjątkowo dobrze widoczny w przypadku fandomu Ataku Tytanów.

\section{JSDF w krainie Tytanów}

We wrześniu 2009 roku opublikowany został pierwszy tom postapokaliptycznej mangi autorstwa Isayamy Hajime Atak Tytanów (od maja 2014 roku wydawany również po polsku nakładem wydawnictwa J. P. Fantastica). Licząca obecnie 25 tomów seria zyskała wielką popularność i doczekała się adaptacji w postaci między innymi serialu animowanego, trzech aktorskich filmów kinowych, powieści oraz serii gier. Atak Tytanów opowiada historię nielicznych ludzi, którzy

${ }^{26}$ A. Oros i Y. Tatsumi, Global Security Watch Japan, Santa Barbara 2010, s. 64. 
przetrwali napaść tytułowych kolosów. Pozostali przy życiu chronią się w otoczonych wysokimi murami miastach. Fabuła skupia się na losach przyjaciół służących w oddziale wojska powołanym do walki z Tytanami.

Popularna seria spotkała się z krytyką części odbiorców poza granicami Japonii, uznających przedstawioną historię za promującą militaryzm i nacjonalizm. Ocalałą „ludzkość” interpretowano jako Japonię, a zagrażających jej odczłowieczonych Tytanów jako Chiny i Koreę ${ }^{27}$. W 2013 roku rozgorzała jeszcze bardziej zażarta dyskusja, związana bezpośrednio z poglądami politycznymi autora mangi. Źródłem kontrowersji było nagłośnienie wpisu z 2010 roku zamieszczonego na oficjalnym blogu Isayamy, w którym mówiono, iż jeden z bohaterów (Dot Pixis), wzorowany jest na historycznej postaci Akiyamy Yoshifuru - człowieka „wiodącego skromne życie, którego osoba i postawa godna jest szacunku”28. Tymczasem generał Akiyama pełnił między innymi funkcję dowódcy Armii Japońskiej w Korei w latach 1916-1917 (po aneksji kraju przez Cesarstwo). Akiyama jest postrzegany przez Koreańczyków jako zbrodniarz wojenny, ponieważ był odpowiedzialny za akty przemocy w stosunku do ludności cywilnej. Komentarz Isayamy wywołał oburzenie wśród koreańskich fanów, a autor zaczął otrzymywać wiadomości z pogróżkami, włączając w to groźby śmieci ${ }^{29}$. Sytuacji nie poprawił fakt, iż na twitterowym profilu, powszechnie uważanym za nieoficjalne konto Isayamy, pojawiły się wpisy banalizujące japońskie zbrodnie wojenne w Korei. Podkreślano tam jednocześnie rozwój kraju, którego przyczyną miała być japońska okupacja ${ }^{30}$. Niezależnie od intencji autora można z dużym przekonaniem stwierdzić, że wśród fanów Ataku Tytanów znalazła się grupa o prawicowym i nacjonalistycznym światopoglądzie, którym seria dostarczyła obszernego materiału do promocji przekonań, zwłaszcza w formie fanvidów.

W pracach inspirowanych serią istotną rolę odgrywają utwory muzyczne z anime, z których szczególnie często wykorzystywane są dwie piosenki otwierające: Guren no Yumiya (Purpurowy tuk i strzaty), oraz Shinzō wo Sasageyo (Z serca ofiare złóż), obie wykonywane przez Linked Horizon. Teksty utworów nadają ton wykorzystującym je fanvidom, stanowiąc kluczowy element narra-

27 A. Osmond, Attack on Titan: the Controversy, „Manga UK” 2014, [online:] http://www. mangauk.com/13757/ [data dostępu: 24.06.2018].

${ }^{28}$ H. Isayama, Kōshin ga todokōtte suimasen! Henji shimasu!, Oficjalny Blog Hisayamy, 4.10.2010, [online:] http://blog.livedoor.jp/isayamahazime/archives/3639547.html [data dostępu: 02. 06.2018].

29 Seldomusings, The Possible Disturbing Dissonance Between Hajime Isayama's Beliefs and Attack on Titan's Themes, „Musings That Are Seldom”, 19.10.2013, [online:] https://seldomusings. wordpress.com/2013/10/19/migiteorerno/ [data dostępu: 02.06.2018].

30 Tamże. 
cji politycznej. Ponadto twórcy często kopiują sposób, w jaki animowana jest rozpoczynająca każdy odcinek sekwencja, tworząc jej alternatywną wersję, oraz podkreślając analogię między fabułą Ataku Tytanów a sytuacją Japonii.

Reprezentatywnym przykładem wykorzystania Ataku Tytanów do promocji wizerunku JSDF jako jednostek bojowych, niezbędnych do odparcia potencjalnego ataku wroga, jest Shinkgeki no jieitai full chōkanzenban kai ${ }^{31}$ (Atak na $J S D F$, wersja pełna poprawiona), opublikowany w 2015 roku przez użytkownika GUROTESUKU2000 i liczący ponad 688 tysięcy wyświetleń ${ }^{32}$. Fanvid, wykorzystujący utwór Guren no Yumiya, składa się głównie z krótkich scen (pochodzących z nagrań promocyjnych oraz informacyjnych JSDF), które zmontowano tak, by pasowały do szybkiego rytmu piosenki. O wydźwięku całości decyduje tekst utworu:

\section{Seid ihr das Essen? \\ 2 Nein, wir sind der Jäger!}

3 Nie znając imion zdeptanych kwiatów 4. Wyczekuje podmuchu wiatru stracony z nieba ptak

5 Modlitwy nie zostanq wystuchane

6 Tylko wola walki może zmienić świat

7 Wieprze szydza z pracych naprzód przez stosy trupów

8 Bydło niech trwa w ułudzie komfortu,

9 dla nas wolność głodnych wilków

10 Upokorzenie niewoli stanie się iskrą odwetu

11 Za murami towca dopadnie zwierzyne

12 Ciało rozpalone pragnieniem mordu

13 Przeszyje zmierzch szkartatem

14 Purpurowych tuku i strzaty ${ }^{33}$

31 GUROTESUKU2000, Shinkgeki no Jieitai full Chōkanzenban Kai, 3.03.2015, [film online:] https://www.youtube.com/watch?v=daD2SStSIWA [data dostępu: 01.06.2018].

32 Stan na 1 czerwca 2018.

33 Anime Lyrics, Guren no Yumiya, Anime Lyrics, bdw, [online:] https://www.animelyrics. com/anime/shingeki/gurennoyumiya.jis [data dostępu: 31.05.2018]. Tłumaczenie autorki. 
Wersy, które w oryginalnym kontekście dotyczyły walki ludzi przeciwko Tytanom, zostały tu zinterpretowane jako głos Japonii, która po latach poniżeń ze strony swoich sąsiadów powinna odzyskać pełną suwerenność. Wers siódmy zilustrowany jest zdjęciami przedstawiającymi kolejno: Park Geun-hye, prezydenta Korei Południowej ${ }^{34}$ i Xi Jinpinga - prezydenta Chińskiej Republiki Ludowej (wieprze) oraz Abe Shinzō i Koizumi Shinjirō - jednego z najmłodszych liderów PLD (prący do przodu). Przy wersie ósmym następują sceny z antyjapońskich prostestów w Chinach i Korei (bydło) i wreszcie zdjęcie budynku japońskiego parlamentu (wolność). W zestawieniu tym widać wyraźnie, że twórca fanvida postrzega Chiny i Koreę Południową w sposób jednoznacznie negatywny, jako kraje będące przeszkodą na drodze Japonii do pełnej wielkości. Obecny rząd PLD przedstawiony jest jako prowadzący kraj we właściwą stronę, ku sile wynikającej również z rozwoju wojskowości.

Medialny wizerunek JSDF bazuje na konstytucyjnym pacyfizmie, a kampanie promocyjne organizacji zawierają liczne sceny z akcji humanitarnych oraz motta zachęcające do wstąpienia do sił zbrojnych, takich jak „By wspierać i kochać”, „Bo jest ktoś, kogo chcę chronić”, „Dla ukochanych ludzi, dla ukochanego kraju”35. Nie przeszkadza to autorowi fanvida łączyć filmów promocyjnych JSDF z archiwalnymi materiałami z okresu w wojny w Azji i na Pacyfiku (1931-1945), ukazującymi członków Cesarskiej Armii Japonii. Agresywna wojna prowadzona w ramach kolonialnych ambicji Cesarstwa Japońskiego widziana jest przez nacjonalistów ,jako wojna prowadzona w samoobronie, albo wojna w celu wyzwolenia Azji spod panowania zachodniego imperializmu"36. Fanvid podkreśla ciągłość pomiędzy JSDF a Armią Cesarską, choć bez wyraźnej sugestii, czy JSDF bliżej do czynnej armii, czy też Cesarska Armia Japonii walczyła w obronie ojczyzny. Ukazanie obu grup w spójnej, wyraźnie pozytywnej, bohaterskiej narracji (niezależnie od tego, czy w kontekście propagowania remilitaryzacji, czy też rewizjonizmu historycznego) jest wyrazem poparcia dla retoryki konserwatywnej prawicy.

Twórcy fanvidów wykorzystujących Atak Tytanów do promocji wizerunku JSDF jako wyposażonych w najnowsze technologie i bohaterskich sił zbrojnych, nieczęsto uwzględniają w swoich montażach jakiekolwiek debaty społeczne i polityczne na temat statusu prawnego tej organizacji. Do wyjątków należy

34 Urzędująca prezydent momencie publikacji fanvida w 2015 roku.

35 Rikujōjieitai kōhō channeru, Rikujōjieitai CM `Mamoritai hito ga iru' 3-bu Ver., 18.03.2010, [film online:] https://www.youtube.com/watch?v=qXTmPdjaxfU [data dostępu: 24.06.2018].

36 A. Takenaka, Japanese Memories of the Asia-Pacific War: Analyzing the Revisionist Turn post-1995, „The Asia-Pacific Journal: Japan Focus”, 2016, 14 (20), nr 8, [online:] http://apjjf. org/2016/20/Takenaka.html [data dostępu: 29.05.2018]. 
[Kakuseiseiyo Nihonjin] Hosshuha Ōen MAD Guren no Yumiya ${ }^{37}$ opublikowane przez Jisedai no Wakamono no Hoshu Channeru we wrześniu 2015 roku. Ta produkcja (również wykorzystuje Guren no Yumiya) nie tylko wyraża poparcie dla Abe i JSDF, ale też sięga po liczne filmy z demonstracji politycznych i przedstawia przeciwników wprowadzenia prawa o obronie kolektywnej jako wrogów, a jego zwolenników jako patriotów, którzy troszczą się o dobro Japonii. Taka dosłowność w nawiązaniu do konkretnych zmian prawnych jest jednak rzadka wśród twórców fanvidów; większość z nich skupia się na ogólnikowym przekazie.

W czerwcu 2018 roku na YouTubie można było znaleźć przynajmniej czternaście fanvidów łączących tematykę Ataku Tytanów z JSDF ${ }^{38}$ (zob. Tabela 1). Wszystkie, zbliżone do siebie pod względem wykonania oraz treści, bardzo pozytywnie prezentują bojową rolę JSDF. Osiem ukazuje kraje sąsiadujące z Japonią (Koreę Północną, Południową oraz ChRL) jako zagrożenie (w tabeli kolumna „zagrożenie kraju"), z czego wszystkie wykorzystywały utwory Guren no Yumiya oraz Shinzō wo Sasageyo. Cztery (wszystkie do Guren no Yumiya) wyrażały jednocześnie poparcie dla rządu PLD (w tabeli: 'prorządowe'). Dobór utworu muzycznego jest zatem kluczowy dla ostatecznego ideologicznego przekazu fanvida. Zestawienie wskazuje ponadto, że choć liczba wyświetleń waha się od zaledwie tysiąca do prawie siedmiuset tysięcy, omawiane produkcje cieszą się pewną popularnością wśród odbiorców ${ }^{39}$, czego przyczyn doszukiwać można się między innymi w popularności samego Ataku Tytanów: na omawiane produkcje może trafić osoba szukająca fanvidów poświęconych tej serii.

37 Jisedai no Wakamono no Hoshu Channeru, [Kakuseiseiyo Nihonjin] Hosshuha ōen MAD Guren no Yumiya, 01.09.2015, [film online:] https://www.youtube.com/watch?v=Fw DBBxBJZ sA\&t=0s\&index=9\&list=PLGsjq2hamWYh3COdFf37LulUA_juKIdO5 [data dostępu: 27.06.2018] .

38 Zestawienie nie uwzględnia kilkunastu fanvidów będących hołdem dla żołnierzy Cesarskiej Armii Japońskiej, jako że skupiają się one na aspekcie historycznym.

39 Dla porównania, z trzydziestu filmów na oficjalnym kanale SEALDs tylko osiem przekroczyło 10 tysięcy wyświetleń, a jeden - 40 tysięcy. 
Pobrane z czasopisma Artes Humanae http://arteshumanae.umcs.pl

ALEKSANDRA JAWOROWICZ-ZIMNY • Politycznie zaangażowane treści...

Tabela 1: Fanvidy poświęcone JSDF nawiązujące do anime „Atak Tytanów”

\begin{tabular}{|c|c|c|c|c|c|c|c|}
\hline & Tytuł & $\begin{array}{l}\text { Nazwa } \\
\text { kanału }\end{array}$ & $\begin{array}{l}\text { Data } \\
\text { zamiesz- } \\
\text { czenia }\end{array}$ & $\begin{array}{l}\text { Liczba } \\
\text { wyświe- } \\
\text { tleń }\end{array}$ & $\begin{array}{l}\text { Wyko- } \\
\text { rzystany } \\
\text { utwór }\end{array}$ & $\begin{array}{l}\text { Zagro- } \\
\text { żenie } \\
\text { kraju }\end{array}$ & $\begin{array}{l}\text { Prorzą- } \\
\text { dowe }\end{array}$ \\
\hline 1 & $\begin{array}{l}\text { [Jieitai MAD] JSDF Shinzō } \\
\text { wo Sasageyo }\end{array}$ & $\begin{array}{l}\mathrm{Su}-\mathrm{PRK} 15 \mathrm{~h} \\
\mathrm{~s}\end{array}$ & 25.06.2017 & 87215 & $\begin{array}{l}\text { Shinzō wo } \\
\text { Sasageyo }\end{array}$ & tak & - \\
\hline 2 & $\begin{array}{l}\text { Shingeki no Jieitai Full } \\
\text { Chōkanzenban kai }\end{array}$ & $\begin{array}{l}\text { GUROTE- } \\
\text { SUKU2000 } \\
\end{array}$ & 03.03 .2015 & 692793 & $\begin{array}{l}\text { Guren no } \\
\text { Yumiya }\end{array}$ & tak & tak \\
\hline 3 & $\begin{array}{l}\text { [Kakuseiseyo nihonjin] } \\
\text { Hoshuha Ōen MAD Guren } \\
\text { no Yumiya }\end{array}$ & $\begin{array}{l}\text { Jisedai no } \\
\text { Wakamono } \\
\text { no Hoshu } \\
\text { Channeru }\end{array}$ & 01.09 .2015 & 5308 & $\begin{array}{l}\text { Guren no } \\
\text { Yumiya }\end{array}$ & tak & tak \\
\hline 4 & $\begin{array}{l}\text { Guren no Zahyō Maddo Tai- } \\
\text { heiyōsensō: Jieitai Heiwa to } \\
\text { Iu Zahyō Megakete } \sim\end{array}$ & $\begin{array}{l}\text { kezu } 0120 \\
\text { ZERO }\end{array}$ & 21.05.2018 & 6418 & $\begin{array}{l}\text { Guren no } \\
\text { Zahyō }\end{array}$ & - & - \\
\hline 5 & $\begin{array}{l}\text { [Maddo Jieitai] Shingeki no } \\
\text { Sakimori } \amalg\end{array}$ & $\begin{array}{l}102 \text { tai The- } \\
\text { Sampson } \\
\end{array}$ & 22.10 .2015 & 1046 & $\begin{array}{l}\text { Jiyū no } \\
\text { Tsubasa }\end{array}$ & - & - \\
\hline 6 & $\begin{array}{l}\text { MAD Jieitai] Shingeki no } \\
\text { Sakimori }\end{array}$ & $\begin{array}{l}102 \text { tai The- } \\
\text { Sampson }\end{array}$ & 08.03.2015 & 1609 & $\begin{array}{l}\text { Guren no } \\
\text { Yumiya }\end{array}$ & - & - \\
\hline 7 & $\begin{array}{l}\text { Nipponkoku Jieitai pv Kyoku } \\
\text { 'Guren no Yumiya' }\end{array}$ & $\begin{array}{l}\text { JPNsaki- } \\
\text { mori2 } \\
\end{array}$ & 22.07.2013 & 58528 & $\begin{array}{l}\text { Guren no } \\
\text { Yumiya }\end{array}$ & tak & tak \\
\hline 8 & $\begin{array}{l}\text { Hangeki no Sakimori - Jieit- } \\
\text { ai Guren no Yumiya MAD }\end{array}$ & \begin{tabular}{|l} 
Yamato \\
minzokū \\
samurai
\end{tabular} & 28.12.2017 & 11668 & $\begin{array}{l}\text { Guren no } \\
\text { Yumiya }\end{array}$ & tak & - \\
\hline 9 & $\begin{array}{l}\text { [Jieitai Maddo] Yōgeki no } \\
\text { Küji [Shingeki no Kyojin Jiyū } \\
\text { no Tsubasa] }\end{array}$ & nagamon1 & 14.08.2013 & 105450 & $\begin{array}{l}\text { Jiyū no } \\
\text { Tsubasa }\end{array}$ & - & - \\
\hline 10 & $\begin{array}{l}{[M A D] \text { Kaijōjieitai Jiyū no }} \\
\text { Tsubasa }\end{array}$ & J mamor & 14.11 .2015 & 13429 & $\begin{array}{l}\text { Jiyū no } \\
\text { Tsubasa }\end{array}$ & - & - \\
\hline 11 & $\begin{array}{l}\text { [Jieitai Maddo] Shingeki no } \\
\text { Kyojin Season } 2 \text { OP "Shinzō } \\
\text { wo Sasageyo" }\end{array}$ & $\begin{array}{l}\text { Takahashi } \\
\text { ryōsuke }\end{array}$ & 17.05.2017 & 83772 & $\begin{array}{l}\text { Shinzō wo } \\
\text { Sasageyo }\end{array}$ & tak & - \\
\hline 12 & $\begin{array}{l}\text { [Jieitai Maddo] Shingeki no } \\
\text { Kyojin 2-ki OP "Shinzō wo } \\
\text { Sasageyo" Furu }\end{array}$ & DDH & 13.06.2017 & 97124 & $\begin{array}{l}\text { Shinzō wo } \\
\text { Sasageyo }\end{array}$ & tak & - \\
\hline 13 & $\begin{array}{l}\text { [Jieitai] Shingeki no Kyojin } \\
\text { (Shingeki no Jieitai) }\end{array}$ & mmcpQ & 24.04 .2013 & 196374 & $\begin{array}{l}\text { Guren no } \\
\text { Yumiya }\end{array}$ & tak & tak \\
\hline 14 & $\begin{array}{l}\text { [Jieitai] Shingeki no Kyojin } \\
\text { 2-ki OP "Shinzō wo Sasageyo" } \\
\text { (Shisaku 2) }\end{array}$ & $\begin{array}{l}\text { Channel } \\
\text { NAGATO }\end{array}$ & 26.05.2017 & 8728 & $\begin{array}{l}\text { Shinzō wo } \\
\text { Sasageyo }\end{array}$ & tak & - \\
\hline
\end{tabular}

Wspierając premiera - fanvidy poświęcone PLD

Drugim, choć nieco mniej popularnym nurtem łączącym Atak Tytanów z polityką Japonii, są fanvidy wyrażające poparcie dla PLD i premiera Abe. W czerwcu 2018 roku na YouTubie można było znaleźć dwie takie produkcje, a kolejne cztery na NicoNico Dōga. W naturalny sposób znalazł tu zastosowanie, popu- 
larny również w montażach poświęconych JSDF, utwór Shinzō wo Sasageyo, do którego wykonano pięć z sześciu fanvidów ${ }^{40}$. Fani wykorzystali tu homofoniczność występującego w oryginale słowa shinzō (心臓), oznaczającego serce, oraz zapisywanego innymi znakami imienia premiera Japonii, Abe Shinzō (晋三). W tytułach fanvidów oryginalna pisownia shinzō zastąpiona została imieniem, a w jednym z wariantów zmieniono także występującą w tytule partykułę wo na ni (Shinzō ni... zamiast Shinzō wo...), co nadaje tekstowi znaczenie 'Ofiaruj się Shinzō'. Podobnie jak Guren no Yumiya, tekst utworu wzywa do poświęcenia i walki w obliczu zewnętrznego zagrożenia:

1 Chcieliśmy uwierzyć że nie może gorzej być

2 A jednak zaskoczyt nas najgorszy dla nas dzień

3 Walenie do bram bezlitośnie szarpie nasze nerwy 4 Zapowiedź katastrofy pochtonie nas jak koszmarny sen

5 Wrogiem nam, kto zdrady raz dopuścit się! Powalimy ich!

6 Jaka twarz, jaki wzrok przeszywat nas tamtego dnia?

7 Aby diabła nam pokonać, cóż poświęcić trzeba?

8 Choćby i życie! Choćby i duszę! Nie zawaham się!

9 Ofiarę złóż, ofiarę złóż! Z serca ofiare złóż!

10 Taka chwila wymaga catkowitego poświęcenia

11 Ofiare złóż, ofiare złóż! Z serca ofiarę złóż!

12 Stwórz wyśniona przysztość własnymi rękoma

Dość prostym przykładem wykorzystania utworu jako swego rodzaju „hołdu” dla premiera jest dostępny na YouTubie fanvid [Shingeki no Kyojin] Abe Shinzō wo Sasageyo ${ }^{41}$ ([Atak Tytanów] Ofiaruj [się] Abe Shinzō), opublikowany przez użytkownika \#paeriatomōshimasu 6 maja 2017 roku. Twórca nałożył na oryginalną animację zdjęcia przedstawiające premiera, spośród których szczególną uwagę zwraca kończąca montaż fotografia, która nawiązuje do innego, tym razem zachodniego dzieła popkultury. Komputerowo zmodyfikowana grafika

40 W ostatnim wykorzystano Guren no Yumiya.

41 \#Paeriatomōshimasu, Shingeki no Kyojin] Abe Shinzō wo sasageyo!, 06.05.2017, [film online:] https://www.youtube.com/watch?v=AuKLNOm7lKc [data dostępu: 01.06.2018]. 
przedstawia bohaterów filmu The Avengers (2012), których twarze zastąpiono zdjęciami najważniejszych polityków PLD z Abe na czele, dodając podpis „Abengers". Dzięki dodatkowemu nawiązaniu popkulturowemu fanvid przedstawia premiera Abe z sympatią, jednak nie nawiązuje przy tym w dosłowny sposób do kwestii politycznych, wpisując się w raczej rozrywkowy profil kanału użytkownika \#paeriatomōshimasu.

Inaczej wygląda kwestia z wykorzystującym ten sam utwór montażem [MAD] Shingeki no Kyojin no OP de Shingeki no Nihon [Shinzō ni Sasagego yo] ([MAD] Opening Ataku Tytanów w Ataku na Japonię [Ofiaruj się Shinzō]) ${ }^{42}$, umieszczonym na NicoNico Dōga w dniu 17 maja 2017 roku przez użytkownika Burakku Rokku Azunyan. Obszerne fragmenty pierwszej zwrotki (wersy 1-8) zilustrowane są nagraniami ćwiczeń armii północnokoreańskiej oraz chińskiej, a także wystąpień przywódców tych krajów. Szybko zmieniające się w rytm muzyki ujęcia czołgów, myśliwców oraz maszerujących wojsk budują napięcie oraz poczucie zagrożenia. Refren (wersy 9-12) przedstawia Abe w otoczeniu JSDF, podkreślając kluczową dla Japonii rolę rozwoju militarnego. Wymagająca poświęcenia „chwila” z tekstu piosenki zilustrowana jest sceną wybuchu bomby atomowej, nadając fanvidowi wyraziste przesłanie: w obliczu rozwoju programów nuklearnych sąsiednich państw Japonia potrzebuje silnego wojska, gotowego w każdej chwili do obrony państwa przed wrogiem. Półtoraminutowy fanvid z dużą dosłownością wyraża cele rządu Abe w zakresie rozwoju militarnego. Czyni to jednocześnie w wyrazisty, emocjonalny sposób, co zwiększa jego szanse na dotarcie do młodszych odbiorców.

\section{Wnioski}

Gloryfikująca militaryzm fabuła Ataku Tytanów wzbudziła kontrowersje poza granicami Japonii oraz skłoniła część odbiorców do dociekań, na ile skojarzenia z sytuacją polityczną kraju były zamierzone przez autora. Niezależnie jednak od trudnych do udowodnienia intencji Isayamy, fani o prawicowych oraz nacjonalistycznych poglądach uczynili Atak Tytanów, a zwłaszcza jego animowaną adaptację, flagowym dziełem popkultury służącym do promocji bliskich im idei. Wykorzystanie serii w tym właśnie celu jest bardzo dobrze widoczne na przykładzie fanvidów. Stosunkowo proste do wykonania, szeroko dostępne

${ }^{42}$ Burakku Rokku Azunyan, [MAD] Shingeki no Kyojin no OP de Shingeki no Nihon [Shinzō ni Sasagego yo], 17.05.2017, [film online:] http://www.nicovideo.jp/watch/sm31231880 [data dostępu: 24.06.2018]. 
dzięki obecności na platformie YouTube oraz wykorzystujące pełną patosu i charakteryzującą się sugestywnym tekstem muzykę $\mathrm{z}$ anime, fanvidy umożliwiają podzielenie się wyrazistym przekazem ideologicznym z relatywnie dużą grupą odbiorców.

To właśnie oglądalność politycznie zaangażowanych fanvidów nawiązujących do popularnych dzieł popkultury jest szczególnie istotna w dyskusji na ich temat. Znalezienie i obejrzenie w Internecie nagrania poświęconego dyskusji politycznej (niezależnie od jej ideologicznego profilu) wymaga świadomego poszukiwania treści danego typu. Odbiorca musi wpisać słowa kluczowe związane z polityką, aby trafić na wideo SEALDs wyjaśniające konsekwencje zmian prawnych dotyczących obrony kolektywnej. Równie aktywnie musiałby poszukiwać jednego z licznych nagrań osób o prawicowych poglądach, tłumaczących przykładowo, dlaczego Japonia powinna zdecydować się na program nuklearny. Istnieje dość niewielkie prawdopodobieństwo odkrycia takich treści przez przypadek, bez wcześniejszego zainteresowania polityką. Inaczej jest w przypadku fanvidów nawiązujących do tak popularnego tytułu jakim jest Atak Tytanów. Forma fanvida jednocześnie zwiększa grono odbiorców i upraszcza przekaz, stawiając na komunikat emocjonalny bardziej niż intelektualny.

Wykorzystując wątki z Ataku Tytanów, fanvidy skupiają się na wizji silnego państwa z silnym przywódcą na czele, odwołując się do emocji takich jak duma narodowa i poczucie zagrożenia. Nastawione są ponadto na estetykę, pokazując nowoczesne wojskowe wyposażenie, oddziały w paradnych mundurach oraz spektakularne akcje. Również kadry przedstawiające polityków często uzupełnione są o efekty specjalne, uatrakcyjniające całość montażu. Mimo braku merytorycznej argumentacji, pozostają one fanowską formą promocji części idei rozpowszechnianych przez rząd Abe, zwłaszcza remilitaryzacji oraz nacjonalizmu.

Jak pokazują przykłady SEALDs i pokrewnych organizacji, walka liberalnej młodzieży odbywa się raczej na płaszczyźnie fizycznej, a świat wirtualny wykorzystywany jest najczęściej jako pole do rzeczowej argumentacji i edukacji. W sieci trudno zauważyć produkcje promujące lewicowe i liberalne poglądy przy wykorzystaniu produkcji popkulturowych, która to metoda pozostaje popularna raczej wśród młodzieży konserwatywnej. Ustalenie, na ile kontakt z politycznymi fanvidami może kształtować poglądy odbiorców, wymaga dalszych badań, jednak przykład produkcji nawiązujących do Ataku Tytanów pokazuje, iż wykorzystanie popkultury może uatrakcyjnić polityczny przekaz nadając mu lekką, rozrywkową, ale i emocjonalną formę, a także zwiększyć jego krąg odbiorców, przyciągając uwagę poszukujących rozrywki fanów oryginalnego dzieła. 


\section{Bibliografia}

1. Anime Lyrics, Guren no Yumiya, Anime Lyrics, bdw, [online:] https://www.animelyrics.com/anime/shingeki/gurennoyumiya.jis [data dostępu: 31.05.2018].

2. Anime Lyrics, Shinzō wo sasageyo, Anime Lyrics, bdw, [online:] https://www.animelyrics.com/anime/shingeki/shinzouwosasageyo.htm [data dostępu: 25.06.2018].

3. Brough M. M. i Shresthova S., Fandom Meets Activism: Rethinking Civic and Political Participation, „Transformative Works and Cultures” 2012, nr 10, [online:] http:// journal.transformativeworks.org/index.php/twc/article/view/303/265 [data dostępu: 29.05.2018], DOI:10.3983/twc.2012.030.

4. Burgess J. i Green J., YouTube: Online Video and Participatory Culture, Cambridge 2009.

5. Coppa F., Women, „Star Trek”, and the early development of fannish vidding. „Transformative Works and Cultures" 2008, nr 1, [online:] http://journal.transformativeworks.org/index.php/twc/article/view/44 [data dostępu: 29.05.2018], DOI:10.3983/ twc.2008.0044.

6. Hills M., Fan Cultures, Londyn 2003.

7. Isayama H., Kōshin ga todokōtte suimasen! Henji shimasu!, Oficjalny Blog Hisayamy, 04.10.2010, [online:] http://blog.livedoor.jp/isayamahazime/archives/3639547.html [data dostępu: 02. 06.2018].

8. Ito M., Technologies of the Childhood Imagination: Yu-Gi-Oh!', Media Mixes, and Everyday Cultural Production, [w:] Structures of Participation in Digital Culture, pod red. J. Karaganisa, Nowy Jork 2007, s. 88-111.

9. Ito- M., „As long as it's not Linkin Park Z”: popularity, distinction, and status in the AMV subculture, [w:] Fandom unbound otaku culture in a connected world, pod red. M. Itō, D. Okabe i I. Tsuji, New Haven 2012, s. 275-298.

10. Jenkins H., Star Trek: rerun, reread, rewritten: Fan writing as textual poaching, „Critical Studies in Mass Communication” 1988, 5 (2), s. 88-107.

11. Kingston J., Extremists Flourish in Abe's Japan, „The Asia-Pacific Journal: Japan Focus” 2014, 12 (44), nr 2, [online:] https://apjjf.org/-Jeff-Kingston/4809/article.html [data dostępu: 30. 05.2018].

12. Kingston J., SEALDs: Students Slam Abe's Assault on Japan's Constitution, „The Asia-Pacific Journal: Japan Focus" 2014, 13 (36), nr 1, [online:] https://apjjf.org/-Jeff -Kingston/4371 [data dostępu: 31. 05.2018].

13. Manabe N., Uprising: Music, youth, and protest against the policies of the Abe Shinzo government, „The Asia-Pacific Journal: Japan Focus” 2014, 12(32), nr 3, [online:] https://apjjf.org/2014/12/32/Noriko-Manabe/4163/article.html[data dostępu: 30. 05.2018].

14. Manabe N., The Revolution Will Not be Televised: Protest Music After Fukushima, Oksford 2015.

15. McCormack G., Japan: Prime Minister Abe Shinzo's Agenda, „The Asia-Pacific Journal: Japan Focus" 2016, 14 (24), nr 1, [online:] https://apjjf.org/2016/24/McCormack. html [data dostępu: 30. 05.2018]. 
16. Noppe N., The cultural economy of fanwork in Japan: dojinshi exchange as a hybrid economy of open source cultural goods [praca doktorska], Leuven 2014, [online:] https://lirias.kuleuven.be/handle/123456789/458549 [data dostępu: 29.05.2018].

17. Oros A. i Y. Tatsumi, Global Security Watch Japan, Santa Barbara 2010.

18. Osmond A., Attack on Titan: the Controversy, „Manga UK” 2014, [online:] http:// www.mangauk.com/13757/ [data dostępu: 24.06.2018].

19. Press Freedom in Contemporary Japan, pod red. J. Kingstona, Nowy Jork 2016.

20. Reid R.A., Remaking Texts, Remodeling Scholarship, [w:] Film Remakes, Adaptations and Fan Productions.

21. SEALDs, oficjalna strona internetowa, [online:] https://www.sealds.com/ [data dostępu: 31.05.2018].

22. Seldomusings, The Possible Disturbing Dissonance Between Hajime Isayama's Beliefs and Attack on Titan's Themes, Musings that are seldom, 19.10.2013, [online:] https:// seldomusings.wordpress.com/2013/10/19/migiteorerno/ [data dostępu: 02.06.2018].

23. Siuda P., In pursuit of pop culture: Reception of pop culture in the People's Republic of Poland as opposition to the political system - Example of the science fiction fandom, „European Journal of Cultural Studies” 2014, 17(2), s. 187-208, DOI: 10.1177/1367549413508100.

24. Stańczyk M., Artykut 9. Konstytucji Japonii dotyczacy wyrzeczenia się wojny i posiadania sit zbrojnych - motywy, kierunki i potrzeby interpretacji,„,Rocznik bezpieczeństwa narodowego" 2008, nr 3, s.166-179.

25. Takenaka A., Japanese memories of the Asia-Pacific War: analyzing the revisionist turn post-1995, „The Asia-Pacific Journal: Japan Focus” 2016, 14 (20), nr 8, [online:] http://apjjf.org/2016/20/Takenaka.html [data dostępu: 29.05.2018].

26. The Adoring Audience: Fan Culture and Popular Media, pod red. L.A. Lewis, Londyn 1992.

27. Turk T., „Your Own Imagination”: Vidding and Vidwatching as Collaborative Interpretation, „Film \& Film Culture” 2010, nr 5, s. 88-111.

28. Turk T., Metalepsis in Fan Vids and Fan Fiction, [w:] Metalepsis in Popular Culture, pod red. K. Kukkonen i S. Klimek, Berlin 2011, s. 83-103.

\section{Filmy wideo}

1. \#Paeriatomōshimasu, [Shingeki no Kyojin] Abe Shinzō wo sasageyo!, 6.05.2017, [film online:] https://www.youtube.com/watch?v=AuKLNOm7lKc [data dostępu: 01.06.2018].

2. Burakku Rokku Azunyan, [MAD] Shingeki no Kyojin no OP de Shingeki no Nihon [Shinzō ni Sasagego yo], 17.05.2017, [film online:] http://www.nicovideo.jp/watch/ sm31231880 [data dostępu: 24.06.2018].

3. GUROTESUKU2000, Shinkgeki no Jieitai full Chōkanzenban Kai, 03.03.2015, [film online:] https://www.youtube.com/watch?v=daD2SStSIWA [data dostępu: 01.06.2018]. 
4. Jisedai no Wakamono no Hoshu Channeru, [Kakuseiseiyo Nihonjin] Hosshuha ōen MAD Guren no Yumiya, 01.09.2015, [film online:] https://www.youtube.com/ watch?v=FwDBBxBJZsA\&t=0s\&index=9\&list=PLGsjq2hamWYh3COdFf37LuIUA_juKIdO5 [data dostępu: 21.06.2018].

5. Rikujōjieitai kōhō channeru, Rikujōjieitai CM `Mamoritai hito ga iru' 3-bu Ver., 18.03.2010, [film online:] https://www.youtube.com/watch?v=qXTmPdjaxfU [data dostępu: 24.06.2018].

6. SEALDs FKA SASPL, [Hontō ni tomeru] Roppun de wakaru anpohōsei, 14.07.2015, [film online:] https://www.youtube.com/watch?time_continue $=42 \& v=6 \mathrm{LuZDH}-$ OGHOE [data dostępu: 31.05.2018].

7. SEALDs FKA SASPL, SEALDs "TO BE", 14.08.2016, [film online:] https://www. youtube.com/watch?time_continue=70\&v=Xl6GtoAb_dM [data dostępu: 31.05.

Summary: Over the last few years anime series Attack on Titan has become one of the biggest hits among Japanese pop cultural products. Its narrative, combining elements of fantasy and post-apocalyptic genres, inspired great number of derivative fan productions, including numerous fan videos. The article presents how fan videos' creators refer (particularly with the music and video footage editing style) to Attack on Titan to promote conservative and nationalistic political agenda. Such fan works express support for Japan's remilitarization, represent neighborly countries (South Korea, People's Republic of China) as hostile and finally support Abe Shinzō's government, presenting him as strong leader. While most liberal youth choose real-world activism and factual debates about Japan's political future, pop cultural references and the Internet became areas for conservative and nationalistic propaganda. Moreover, the form of fan video itself is attractive, emotional and accessible, reaching a wide range of viewers because of the reference to a fandom as popular as Attack on Titan.

Keywords: Japan, pop culture, nationalism, fan cultures, fan videos, militarism 